Check for updates

Cite this: RSC Adv., 2017, 7, 54361

Received 17th September 2017 Accepted 23rd November 2017

DOI: $10.1039 / c 7 r a 10321 b$

rsc.li/rsc-advances

\section{A stable, efficient textile-based flexible perovskite solar cell with improved washable and deployable capabilities for wearable device applications $\uparrow$}

\author{
Jeun-Yan Lam, ${ }^{a}$ Jung-Yao Chen, ${ }^{\mathrm{b}}$ Ping-Chun Tsai, ${ }^{a}$ Yun-Ting Hsieh, \\ Chu-Chen Chueh, (D) *b Shih-Huang Tung (D) *a and Wen-Chang Chen (D)*ab
}

\begin{abstract}
Organic-inorganic hybrid perovskite solar cells (PVSC) have appeared as promising high power-per-weight power systems for wearable electronic devices. Herein, we utilized a low-temperature electrodeposited tin oxide $\left(\mathrm{SnO}_{2}\right)$ electron-transporting layer (ETL) coupled with a thin PCBM ETL and a functional encapsulating layer to realize an efficient, stable textile-based flexible PVSC. We first demonstrated that an easily accessible elastomer can serve as an effective encapsulating material for the fabricated flexible PVSC, as exemplified by the largely improved ambient stability and waterproof properties. Furthermore, we established that the good adhesive properties generated by the elastomer can largely enrich the deployable capability of the completed device stack as evidenced by the effortless integration of a completed device stack onto a textile. As a result, a 15\% textile-based flexible PVSC with improved ambient stability and washable capability was demonstrated. A proof-of-concept device was successfully integrated with other electronic devices on a unitary textile to serve as an efficient power supply system for wearable electronic devices. The findings revealed in this work can promote the future potential applications of PVSCs in wearable device applications.
\end{abstract}

\section{Introduction}

The rapid progress of human civilization has been accompanied with a large demand for energy. Therefore, the development of renewable clean energy has become an urgent issue for this generation. From the sustainable perspective, solar energy has emerged as the most promising candidate due to its almost inexhaustible access and high radiation energy. More importantly, it requires no extra fuels and produces few by-products when supplying power silently.

Among the rapid tide of photovoltaic techniques, organicinorganic hybrid halide perovskite materials with a formula of $\mathrm{ABX}_{3}\left(\mathrm{~A}=\mathrm{Cs}^{+}, \mathrm{CH}_{3} \mathrm{NH}_{3}{ }^{+}\right.$, or $\mathrm{CH}\left(\mathrm{NH}_{2}\right)_{2}{ }^{+} ; \mathrm{B}=\mathrm{Sn}^{2+}$ or $\mathrm{Pb}^{2+} ; \mathrm{X}=$ $\mathrm{Cl}^{-}, \mathrm{Br}^{-}$, or $\mathrm{I}^{-}$) have recently attracted worldwide attention since they not only possess exceptional opto-physical properties but also own facile solution processability. ${ }^{1-7}$ Such appealing features have enabled them to be considered as the most transformative photovoltaic technology nowadays. ${ }^{7}$ Currently, the state-of-the-art power conversion efficiency (PCE) of the

${ }^{a}$ Institute of Polymer Science and Engineering, National Taiwan University, Taipei 10617, Taiwan.E-mail: shtung@ntu.edu.tw; chenwc@ntu.edu.tw

${ }^{b}$ Department of Chemical Engineering, National Taiwan University, Taipei 10617, Taiwan.E-mail: cchueh@ntu.edu.tw

† Electronic supplementary information (ESI) available. See DOI: 10.1039/c7ra10321b perovskite solar cells (PVSCs) on rigid glass substrates has reached over $22 \%$ despite its only few year's development. ${ }^{8}$

Generally, PVSCs can be divided into two types, n-i-p and p-i$\mathrm{n}$ structures, according to the sequence of the employed chargetransporting layers (CTLs). The prototypal PVSC is based on a conventional n-i-p configuration as evolved from the mesoporous dye-sensitized solar cells (DSSCs), which consists of a transition metal oxide (TMO) scaffold serving as an electrontransporting layer (ETL) at device's bottom side. Originally, the TMO is mainly based on $\mathrm{TiO}_{x}$ and requires elaborate preparation procedures involving high-temperature sintering. ${ }^{5,9-13}$ However, such sophisticated processes would imperceptibly increase the production costs and limit the substrate choice. ${ }^{14}$ Further, it impedes the widespread applications of the derived devices in the flexible and wearable electronics, for which polymeric substrates with low glass transition temperatures were usually employed. ${ }^{15}$ For this reason, versatile lowtemperature procedures are developed for $\mathrm{TiO}_{x}$. One example is that Kim et al. have adopted the atomic layer deposition (ALD) technology to prepare a $\mathrm{TiO}_{x}$ layer ETL at a reduced temperature to realize an efficient (PCE: >12\%) flexible conventional PVSC with satisfactory mechanic stability under 1000 bending cycles for a bending radius of $10 \mathrm{~mm} .{ }^{16}$

Meanwhile, other TMOs besides $\mathrm{TiO}_{x}$ with low-temperature processed capability are continuously exploited in the past few years, such as $\mathrm{ZnO}, \mathrm{SnO}_{2}, \mathrm{Zn}_{2} \mathrm{SnO}_{4}$, and $\mathrm{BaSnO}_{3} \cdot{ }^{17-19} \mathrm{Among}$ them, $\mathrm{SnO}_{x}$-based TMO has attracted the most research 
attention due to its much higher electron mobility than $\mathrm{TiO}_{x}$. Several groups have individually developed distinct synthetic processes to prepare $\mathrm{SnO}_{x}$-based films at reduced temperatures to facilitate their electron-transporting properties to realize efficient PVSCs. ${ }^{\mathbf{2 0} 21}$ Recently, we have also utilized the electrochemical deposition technique to successfully prepare a highquality $\mathrm{SnO}_{2}$ film at a low temperature below $100{ }^{\circ} \mathrm{C}$ to fabricate efficient conventional PVSCs. ${ }^{15}$ These aforementioned achievements in developing efficient low-temperature processed ETLs indeed promote the future applications of PVSCs as promising high power-per-weight energy source for unmanned aerial vehicles for environmental and industrial monitoring, rescue and emergency response, and tactical security applications. $^{22}$

While the current state-of-the-art PCE of PVSC can rival the performance of traditional inorganic photovoltaic techniques, more research focuses in this field have been shifted to improve its long-term device stability. The perovskite materials have been documented to be susceptible to moisture, thermal, and intense illumination. ${ }^{23-27}$ In this regard, the encapsulation of PVSC will play a pivotal role to sustain its long-term stability for real operation. At present, barriers and ALD technologies are the most commonly methods used for device encapsulation. For the device fabricated on the regular rigid substrates, it is quite common to employ a thin glass cover slip to cover the completed device stack, followed by sealing with UV curable epoxy resin. ${ }^{28-30}$ However, the UV exposure procedure needs to be carefully controlled to avoid deteriorating the perovskite layer. As for the flexible devices, the encapsulation is more challenging. Thus far, utilizing membranes ${ }^{31,32}$ or ALD technology are considered as the most feasible approaches for encapsulating flexible PVSCs. ${ }^{29,30,33,34}$

In this study, extended from our previous work, ${ }^{15}$ we employed the electrodeposited $\mathrm{SnO}_{2}$ film onto a flexible substrate to fabricate a flexible PVSC. Surprisingly, it is revealed that the quality of the low-temperature electrodeposited $\mathrm{SnO}_{2}$ film on the flexible substrate is inferior to the case deposited on regular rigid substrate, attributed to the lower conductivity of ITO on the flexible substrate. Fortunately, this deficiency can be compensated by introducing an additional fullerene layer on top of $\mathrm{SnO}_{2}$ film, as a common strategy adopted in regular conventional PVSCs. Furthermore, we manifested that an easily accessible elastomer can effectively encapsulate the fabricated flexible PVSC, as exemplified by its largely improved ambient stability and waterproof property. More intriguingly, its respectable adhesive property can also facilitate the effortless integration of the completed device stack onto a textile substrate. As a result, a 15\% textile-based flexible PVSC with improved ambient stability and washable capability was demonstrated. A proof-of-concept device was successfully integrated with other electronic devices on a unitary textile to serve as an efficient power supply system, demonstrating its promising potential for the wearable device applications.

\section{Results and discussion}

Recently, we have employed a low-temperature electrodeposited $\mathrm{SnO}_{2}$ film to serve as an efficient ETL to realize an efficient PVSC on regular rigid ITO substrate. ${ }^{15}$ Regarding its low-temperature manufacturing process, we continuously explored its efficacy in fabricating efficient flexible PVSCs. An ITO/polyethylene naphthalate (PEN) substrate was herein chose to compare with the regular rigid ITO/glass substrate. It has been acknowledged that the ITO/flexible substrates (like PEN, terephthalate (PET), and polyimide (PI))-based devices typically possess inferior performance compared to the rigid ITO/glass counterparts due to the brittle and unsatisfactory bendable nature of ITO. ${ }^{35}$

Fig. 1 presents the high-resolution TEM (HR-TEM) image and selected area electron diffraction (SAED) of the prepared $\mathrm{SnO}_{2}$ film. As can be seen, the inset fast Fourier transform (FFT) pattern shows clear ring patterns associated with diffraction spots. It indicates the highly crystalline structures of $\mathrm{SnO}_{2}$ with random orientation, being consistent to the morphology observed in the HR-TEM image.

We first surprisingly observed that the quality of the electrodeposited $\mathrm{SnO}_{2}$ on the ITO/PEN substrate is much worse than the film deposited on the regular ITO/glass substrate. In contrast to the homogeneous surface morphology observed in the rigid substrate (Fig. $\mathrm{S} 1 \dagger$ ), the morphology of the $\mathrm{SnO}_{2}$ deposited on the ITO/PEN substrate is quite discrete and isolated island-like domains was clearly observed as shown in Fig. 2a. This discrepancy might originate from the lower conductivity of ITO on PEN than on glass since the brittleness of ITO might engender more defects existed in the substrate, which unavoidably leads to the less efficient electrodeposition of $\mathrm{SnO}_{2}$ film. Such incomplete surface coverage will also deteriorate the performance of its derived PVSC because the pinhole formation could easily incur the shunting paths in the device.

To address this deficiency, we therefore introduced an additional PCBM layer onto the deposited $\mathrm{SnO}_{2}$ layer. The fullerene materials have not only been demonstrated as efficient ETLs for PVSCs, ${ }^{36,37}$ but also been proven as sufficient surface modifiers of TMO-based ETLs to facilitate the charge transfer and transport between them and perovskite in the conventional n-i-p PVSCs. ${ }^{38}$ Shown in Fig. $2 b$ and $c$ are the SEM surface images of the $\mathrm{SnO}_{2} / \mathrm{PCBM}$ and simplex PCBM layers deposited on the ITO/PEN substrates, respectively. As can be seen, the simplex PCBM clearly exhibited a featureless surface morphology, revealing its superior film formation capability. After adding this layer onto the pre-electrodeposited $\mathrm{SnO}_{2}$ layer,

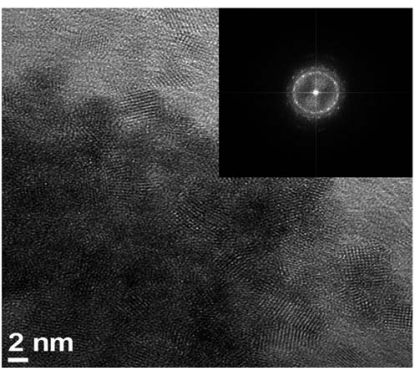

Fig. 1 HRTEM micrograph of the electrodeposited $\mathrm{SnO}_{2}$ film with the corresponding insert FFT pattern. 
(a)

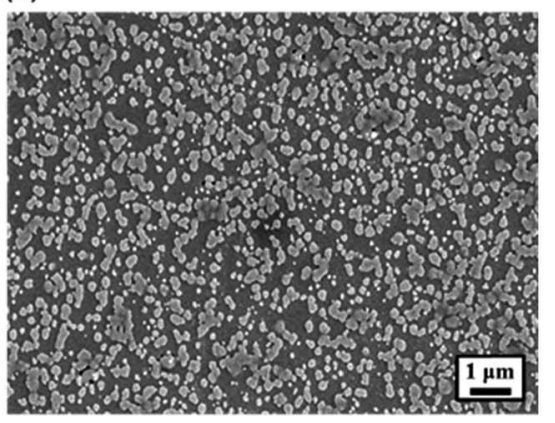

(b)

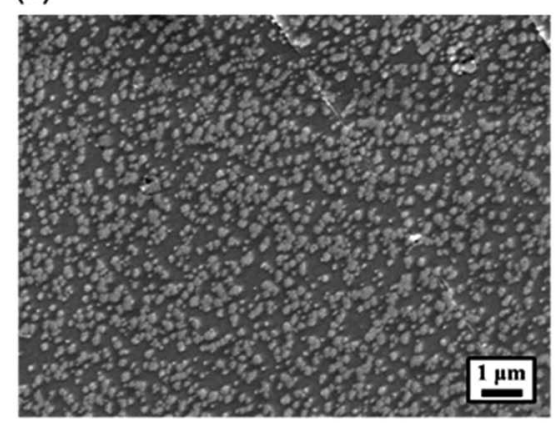

(c)

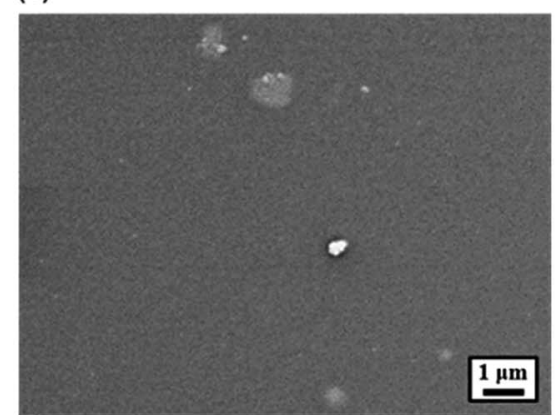

Fig. 2 The top-view SEM image of (a) the electrodeposited $\mathrm{SnO}_{2}$, (b) the electrodeposited $\mathrm{SnO}_{2} / \mathrm{PCBM}$, and (c) PCBM films on the ITO/PEN flexible substrate.

the originally rough surface was kind of flattened and the pristine sharp edges of discrete $\mathrm{SnO}_{2}$ domains was smoothened, indicating that PCBM layer covered the entire surface to avoid any direct contact between perovskite and ITO electrode.

The local surface morphology of these studied ETLs on the ITO/PEN substrate was further characterized using AFM as presented in Fig. 3. As seen, the in-plane continuity of the prepared films is identified, wherein the discrete large grains were observed in the $\mathrm{SnO}_{2}$ film, consistent with its corresponding SEM image (Fig. 2a). Notably, the root-mean-squire (RMS) roughness $\left(R_{\mathrm{q}}\right)$ for the $\mathrm{SnO}_{2}$ film and $\mathrm{SnO}_{2} / \mathrm{PCBM}$ film was evaluated to be $19.4 \mathrm{~nm}$ and $12.1 \mathrm{~nm}$, respectively. The significant decrease in $R_{\mathrm{q}}$ affirms the passivation function of the PCBM layer. The smoothened surface of this bilayered ETL is essential for realizing homogeneous deposition of perovskite to result in high performance.

In addition to the morphological issue, high transparency is another important index for a qualified ETL for achieving high (a)

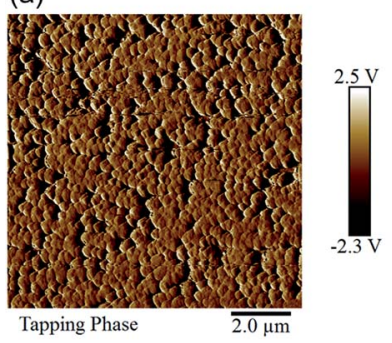

(b)

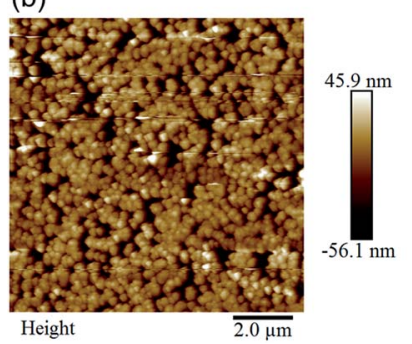

(c)

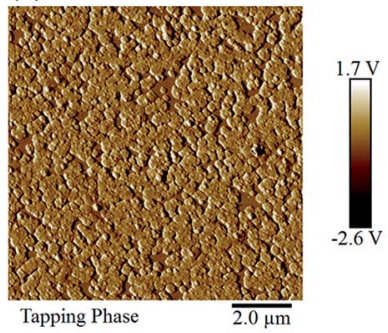

(d)

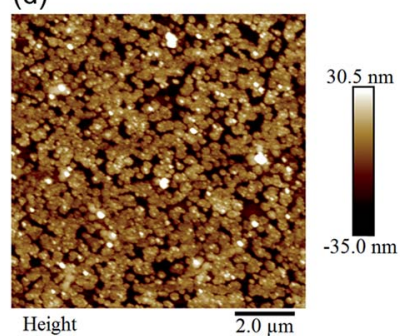

Fig. 3 The AFM phase ( $a$ and $c$ ) and height ( $b$ and $d$ ) images of the electrodeposited $\mathrm{SnO}_{2}$ film ( $a$ and b) and the electrodeposited $\mathrm{SnO}_{2} /$ PCBM (c and d) layers on the ITO/PEN flexible substrate.

efficiency since it can prevent the parasitical absorption of perovskite absorber. Fig. 4a compared the transmittance spectra of the electrodeposited $\mathrm{SnO}_{2}$ and the electrodeposited $\mathrm{SnO}_{2} /$ PCBM films on the ITO/PEN substrates. As can be seen, the bilayered ETL can still possess a reasonable transmittance of $\sim 80 \%$ in the range of wavelengths large than $600 \mathrm{~nm}$ despite the slightly decreased transmittance below $600 \mathrm{~nm}$ as a result of the absorption of the PCBM layer. Note that the transmittance

(a)

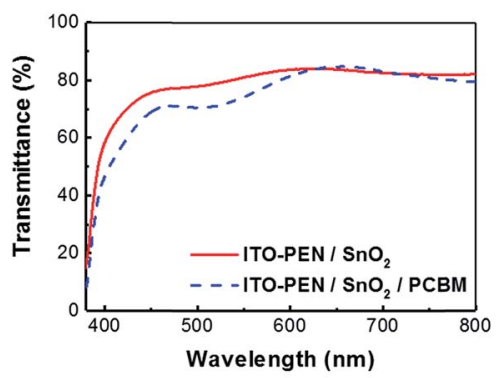

(b)

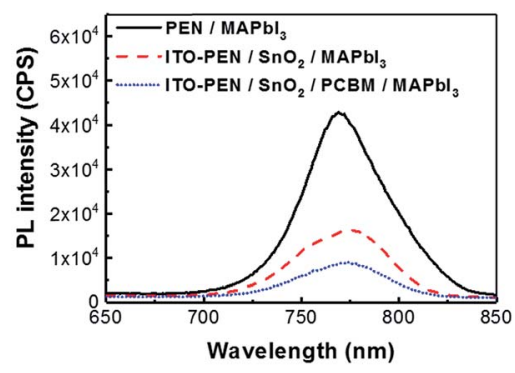

Fig. 4 (a) The optical transmittance of the studied ETLs deposited on ITO/PEN substrate and (b) the PL spectra of perovskite and perovskite deposited on the studied ETLs. 


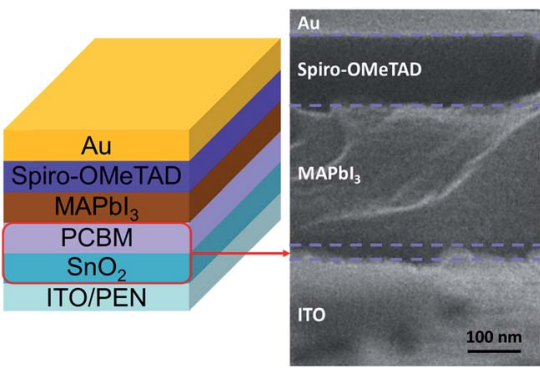

Fig. 5 Device structure and the corresponding cross-sectional SEM image.

dramatically decreased at $\sim 400 \mathrm{~nm}$ which is attributed to the absorption of ITO/PEN substrate.

In order to evaluate the efficiency of charge transfer between the prepared ETLs and perovskite layer, the photoluminescence (PL) of the ETL/perovskite samples were measured accordingly as portrayed in Fig. 4b. It clearly showed that the PL quenching of $\mathrm{CH}_{3} \mathrm{NH}_{3} \mathrm{PbI}_{3}$ deposited on a $\mathrm{SnO}_{2} / \mathrm{PCBM}$ film is higher than the one grown on a simplex $\mathrm{SnO}_{2}$ film, suggesting the facilitated charge transfer between $\mathrm{SnO}_{2} / \mathrm{PCBM}$ and perovskite. This result is expectable as considering the improvement in morphology as discussed earlier.

To examine the efficacy of the prepared ETLs on a flexible substrates, a convention PVSC consisting of PEN/ITO/studied ETLs/ $\mathrm{CH}_{3} \mathrm{NH}_{3} \mathrm{PbI}_{3} /$ Spiro-OMeTAD/Au (Fig. 5, left) was primarily fabricated and the cross-sectional SEM image of the representative device using $\mathrm{SnO}_{2} /$ PCBM ETL was present in Fig. 5 (right) to illustrate its well mutli-layered architecture, in which the thickness of $\mathrm{SnO}_{2}, \mathrm{CH}_{3} \mathrm{NH}_{3} \mathrm{PbI}_{3}$, and Spiro-OMeTAD is estimated to be $\sim 20 \mathrm{~nm}, 250 \mathrm{~nm}$, and $150 \mathrm{~nm}$, respectively. (a)

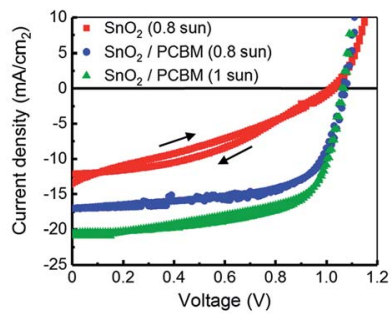

(b)

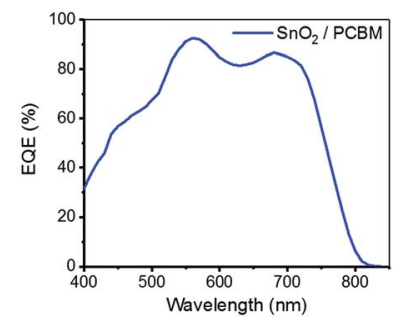

Fig. 6 (a) The $J-V$ curves of the studied flexible PVSCs using the electrodeposited $\mathrm{SnO}_{2}$ ETL and $\mathrm{SnO}_{2} /$ PCBM ETL. (b) EQE of the PVSC using $\mathrm{SnO}_{2} / \mathrm{PCBM}$ ETL under 1 sun.

As a point of note, in order to develop a stable flexible PVSC, we capped the completed device with a ductile elastomer (Scheme 1). As discussed earlier, a thin glass cover slip is the most widely adopted encapsulating technique to date. Its rigidity however impedes the further applications on flexible electronics. Hence, the ductile elastomer was chose as the encapsulating material regarding its easy accessibility, decent adhesion, and good isolation for external substances. Shown in Fig. $\mathrm{S} 2 \uparrow$ is the performance comparison of the control devices using a glass slide and an elastomer as the encapsulating layer. Encouragingly, both encapsulating materials can yield similar performance, qualifying the commercial elastomer as a feasible encapsulating material. Provided the good adhesive property of the elastomer, it might not only can serve as a laudable encapsulating material for flexible PVSCs but also can facilitate the fabrication of textile-based PVSCs (Scheme 1), enriching their application values.

Fig. 6 a presented the $J-V$ characteristics of the encapsulated flexible PVSCs using different ETLs measured under 0.8 sun and
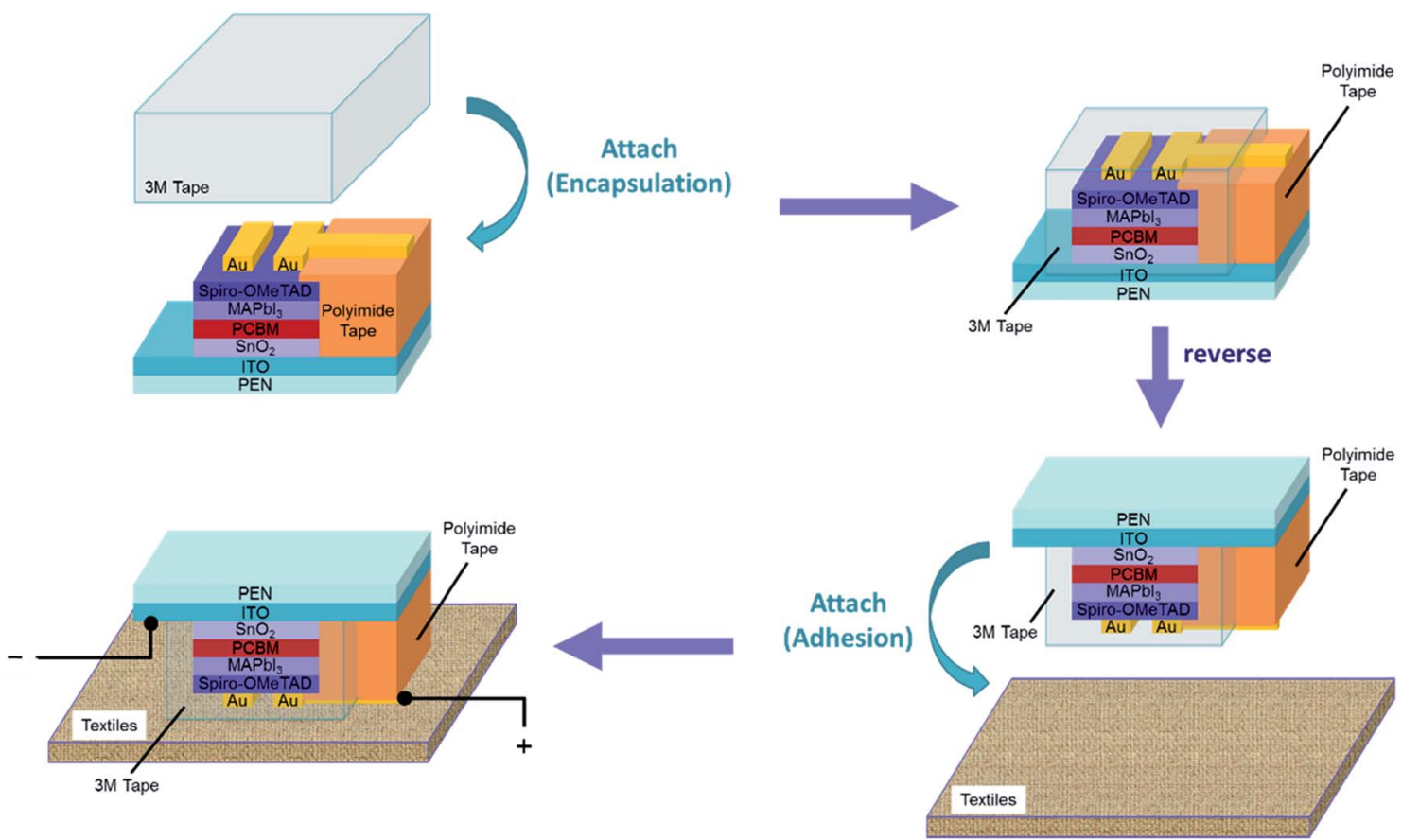

Scheme 1 Illustration of the fabrication of the textile-based flexible PVSC via a functional encapsulating layer in this work. 
Table 1 Device parameters of the studied flexible PVSCs using $\mathrm{SnO}_{2}$ $\mathrm{ETL}$ and $\mathrm{SnO}_{2} /$ PCBM ETL

\begin{tabular}{llllll}
\hline $\begin{array}{l}\text { Electron-transporting } \\
\text { layer }\end{array}$ & & $\begin{array}{l}V_{\mathrm{OC}} \\
(\mathrm{V})\end{array}$ & $\begin{array}{l}J_{\mathrm{SC}} \\
\left(\mathrm{mA} \mathrm{cm}{ }^{-2}\right)\end{array}$ & $\mathrm{FF}$ & $\begin{array}{l}\text { PCE } \\
(\%)\end{array}$ \\
\hline $\mathrm{SnO}_{2}(0.8 \text { sun })^{b}$ & $\mathrm{~F}^{a}$ & 1.03 & -13.47 & 0.31 & 5.4 \\
$\mathrm{SnO}_{2} / \mathrm{PCBM}(0.8$ sun $)$ & $\mathrm{R}^{a}$ & 1.02 & -12.16 & 0.41 & 6.3 \\
& $\mathrm{~F}^{a}$ & 1.08 & -17.07 & 0.63 & 14.5 \\
$\mathrm{SnO}_{2} / \mathrm{PCBM}(1$ sun $)$ & $\mathrm{R}^{a}$ & 1.06 & -17.05 & 0.65 & 14.8 \\
& $\mathrm{~F}^{a}$ & 1.07 & -20.90 & 0.62 & 13.9 \\
& $\mathrm{R}^{a}$ & 1.06 & -20.53 & 0.66 & 14.3
\end{tabular}

${ }^{a}$ F: forward-bias sweep $(-0.1 \mathrm{~V} \rightarrow 1.2 \mathrm{~V})$; R: reverse-bias sweep $(1.2 \mathrm{~V} \rightarrow$ $-0.1 \mathrm{~V}) .{ }^{b}$ Time of electrodeposition for $\mathrm{SnO}_{2}: 120 \mathrm{~s}$.

1.0 sun illumination and the corresponding photovoltaic parameters are summarized in Table 1. It is deserved to mention that we found out there is no performance difference before and after integrating the encapsulated PVSC on the textile (Scheme 1). This result reflects the merit of using elastomer as the encapsulating materials and demonstrates its convenience of integration onto arbitrary substrates.

As clearly shown, under 0.8 sun illumination, the control device using simplex electrodeposited $\mathrm{SnO}_{2}$ ETL yielded a low photocurrent along with a poor fill factor (FF), which can be traced to the high series resistance $\left(R_{\mathrm{S}}\right)$ and low shunt resistance $\left(R_{\mathrm{sh}}\right)$ caused by low-quality $\mathrm{SnO}_{2}$ layer as discussed earlier. Its discontinuous morphology associated with isolated island-like domains impedes efficient charge transport and beget severe charge recombination. However, after introducing a thin PCBM layer, the resultant performance can be significantly improved. As shown, under 0.8 sun illumination, the $V_{\mathrm{OC}}$ was improved from $1.02 \mathrm{~V}$ to $1.06 \mathrm{~V}, J_{\mathrm{SC}}$ was raised from $12.16 \mathrm{~mA} \mathrm{~cm}^{-2}$ to $17.05 \mathrm{~mA} \mathrm{~cm}{ }^{-2}$, and FF was enhanced from 0.41 to 0.65 , corresponding to an increased PCE from $6.3 \%$ to $14.8 \%$. This result clearly highlights the pivotal role of PCBM in our fabricated flexible device, which not only smoothens the rough surface of electrodeposited $\mathrm{SnO}_{2}$ film but also facilitates the charge transfer and transport at the corresponding interface. While this top-performing device was measured under 1 sun illumination, the resultant $J_{\mathrm{SC}}$ was accordingly increased while the $V_{\mathrm{OC}}$ and FF were remained, for which a PCE of $14.3 \%$ comparable to the value measured under 0.8 sun illumination is obtained. The external quantum efficiency (EQE) spectrum of this optimized $\mathrm{SnO}_{2} / \mathrm{PCBM}$-based device is presented in Fig. $6 \mathrm{~b}$. As seen, it showed a broad photo-response across $400 \mathrm{~nm}$ to $800 \mathrm{~nm}$, in a good agreement with the light-harvesting behavior of $\mathrm{CH}_{3} \mathrm{NH}_{3} \mathrm{PbI}_{3} \cdot{ }^{39}$ We note that the lower EQE efficiency across from $400 \mathrm{~nm}$ to $520 \mathrm{~nm}$ might be ascribed to the parasitic absorption from the hybrid ETL and the substrate and the dip at $\sim 630 \mathrm{~nm}$ might be attributed to the reduced absorption of the perovskite as a result of optical interference..$^{40}$

Notably, we also fabricated the devices on the regular ITO/ glass substrate for a fair comparison and the results were shown in Fig. S3 and Table S1. $\dagger$ As shown, different to the case of using flexible substrate, there is only slight performance difference between the $\mathrm{SnO}_{2}$-based device and $\mathrm{SnO}_{2} / \mathrm{PCBM}$-based device. Both devices exhibited hysteresis-free $J-V$ characteristics and yields PCEs of $\sim 14 \%$. This suggests the high-quality $\mathrm{SnO}_{2}$ can be successfully achieved on the ITO/glass substrate through electrodeposition ${ }^{15}$ and the additional PCBM interlayer therefore plays a less important role. On the other hand, we have also investigated the feasibility of replacing $\mathrm{SnO}_{2}$ ETL with a PCBM ETL on the flexible ITO/PFN substrate. As shown in Fig. S4 and Table S2, $\uparrow$ the device using a simplex PCBM ETL yield a lower $J_{\mathrm{SC}}$ than the $\mathrm{SnO}_{2}$-based devices. In addition, it showed severe device hysteresis as reported in the literature. ${ }^{41}$

We next evaluated the ambient stability of the fabricated textile-based flexible PVSC. In order to understand the encapsulating efficacy of elastomer, flexible PEN-based devices with and without encapsulation were compared in parallel in an ambient condition with a controlled humidity of $65 \%$. As shown in Fig. 7, the encapsulated textile-based device showed a much enhanced ambient stability, for which over $70 \%$ of initial PCE can be maintained after $425 \mathrm{~h}$ storage. In contrast, the unencapsulated device was quickly degraded within $100 \mathrm{~h}$ due to the poor surface barrier properties of Spiro-OMeTAD ${ }^{42}$ and the fragility of perovskite to oxygen and moisture. ${ }^{43,44}$ As mentioned above, our device shows good performance at first days of operation but possesses poor stability without encapsulation, indicating that SpiroOMeTAD is not suitable for serving as an effective surface barrier for $\mathrm{H}_{2} \mathrm{O}$ and $\mathrm{O}_{2}$ diffusion. Further optimization using more advanced HTLs is in progress in our group.

Besides the ambient stability, we also examined the waterresistance of the textile-based PVSC in an extreme case, for which the whole device stack was immersed into water for a certain period of time as shown in Fig. 8a. Presented in Fig. 8b is a photograph comparing the devices with and without encapsulation. As can be clearly seen, the color of the unencapsulated part was immediately $(<1 \mathrm{~s})$ turned into yellow and
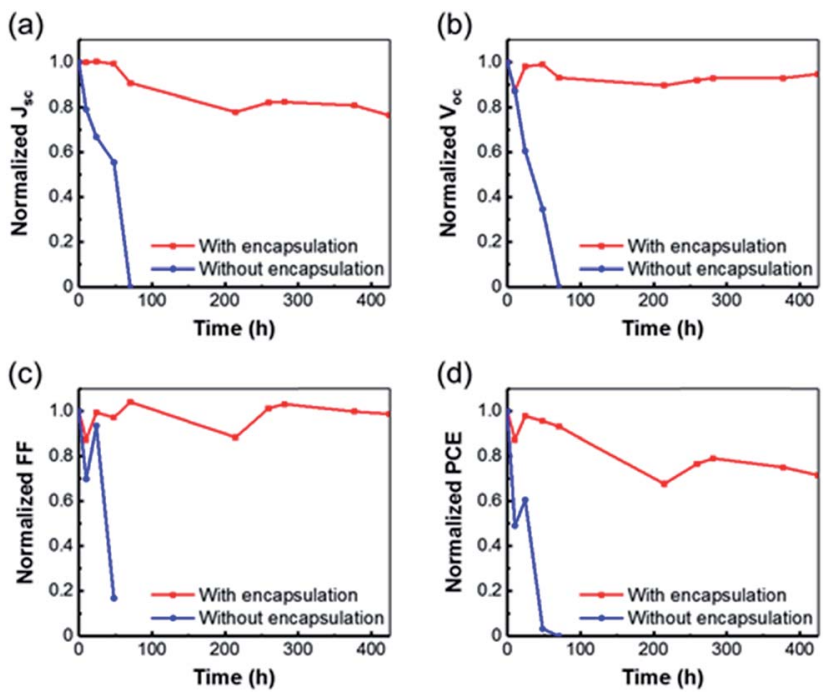

Fig. 7 Device performance of the textile-based flexible PVSC (red square) and the reference PVSC without encapsulation (blue dot) as a function of storage time in an ambient environment (humidity: $\sim 65 \%$; $T=25{ }^{\circ} \mathrm{C}$ ). (a) Normalized $J_{\mathrm{SC}}$, (b) normalized $V_{\mathrm{OC}}$, (c) normalized FF, and (d) normalized PCE. 
(a)

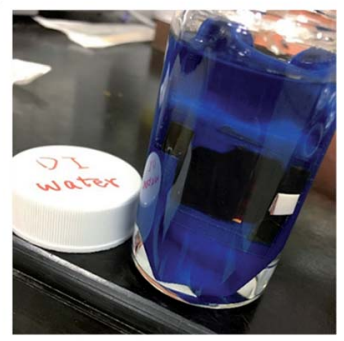

(b)

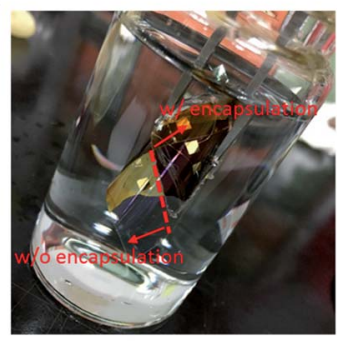

(c)

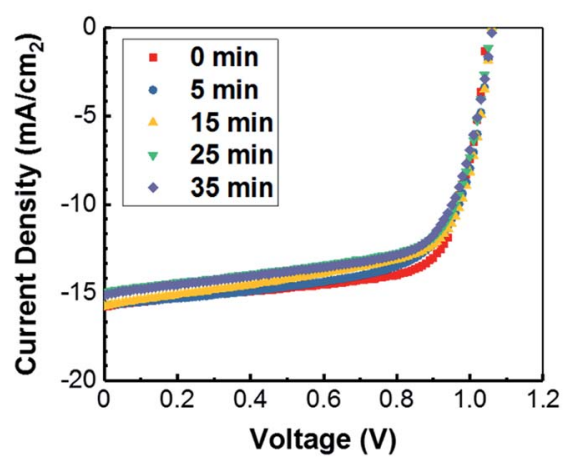

Fig. 8 Photos of (a) the textile-based flexible PVSC immersing in water and (b) a designed device with and without encapsulation immersing in water. (c) The J-V curve of the textile-based flexible PVSC as a function of immersing time in water. (a)

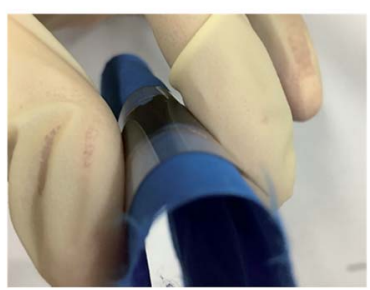

(b)

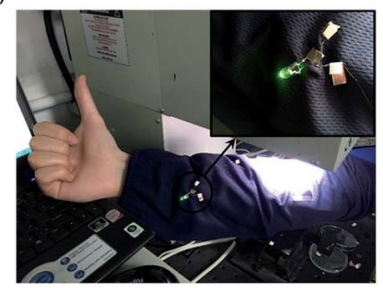

Fig. 9 Photos of (a) the textile-based flexible PVSC and (b) a commercial LED lit up by the fabricated textile-based flexible PVSCS under 0.8 sun illumination.

completely lost the photovoltaic performance. Whereas, the encapsulated device can still preserve a comparable performance after 35 minute immersion in water as displayed in Fig. 8c, for which only a slight decrease in $J_{\mathrm{sc}}$ was observed. These encouraging results manifested that the elastomer can effectively isolate the penetration of air and water into device, enhancing the washable abilities of the encapsulated flexible PVSC, which is very critical for the future potential applications in the wearable devices.

With the successful realization of an efficient textile-based flexible PVSC (Fig. 9a), we further utilized this proof-ofconcept device to demonstrate some possible applications in wearable electronics. For example, we arranged the integrated PVSCs on textile in series connection to successfully light up a commercial light-emitting diode integrated on the same textile as displayed in Fig. 9b. This result suggests our novel device design not only can deliver a stable and efficient flexible PVSC but also can enrich the device's functionality in wearable devices to serve as an efficient power supply system.

\section{Conclusion}

In this work, we successfully developed an efficient textile-based flexible PVSC by employing a low-temperature electrodeposited $\mathrm{SnO}_{2}$ ETL coupled with a thin PCBM ETL and a functional encapsulating layer. Different to our previous work, ${ }^{15}$ we unexpectedly revealed that the quality of the low-temperature electrodeposited $\mathrm{SnO}_{2}$ film on flexible ITO/PEN substrate is inferior to the film deposited on regular rigid substrate, attributed to the lower conductivity of ITO on the flexible substrate. Fortunately, introducing an additional PCBM layer can compensate this deficiency. Besides, we demonstrated that an easily accessible elastomer can effectively encapsulate the fabricated flexible PVSC, as exemplified by the largely improved ambient stability and waterproof property. Moreover, benefiting from its good adhesive property, the completed device stack can be effortlessly integrated onto a textile substrate, showing a much improved deployable capability. As a result, a $\sim 15 \%$ textilebased flexible PVSC with improved ambient stability and washable capability was demonstrated. A proof-of-concept device was successfully integrated with other electronic devices on the textile to serve as an efficient power supply system, demonstrating its promising potential for the wearable device applications.

\section{Experimental}

\section{Preparation of $\mathrm{SnO}_{2}$ via electrodeposition method}

All materials and chemicals were used as received unless stated otherwise. The electrodeposition of $\mathrm{SnO}_{2}$ films on indium tin oxide (ITO)-coated glass substrates follows our previously reported method. ${ }^{15}$ The ITO/PEN substrates were cleaned with detergent and then sequentially ultra-sonicated in deionized water, acetone, and isopropanol for $15 \mathrm{~min}$, respectively. Afterward, the substrates were dried at $120{ }^{\circ} \mathrm{C}$ for $10 \mathrm{~min}$, followed by UV-ozone exposure for $20 \mathrm{~min}$. The electrochemical deposition was performed on a CHI 611D electrochemical analyzer using a three-electrode cell in which ITO was used as a working electrode. A platinum wire was used as a counterelectrode and an $\mathrm{Ag} / \mathrm{AgCl}$ electrode (with a potential at $+0.22 \mathrm{~V}$ vs. standard hydrogen electrode) was used as the reference electrode. The deposition solution is made of $20 \mathrm{mM} \mathrm{SnCl}_{2}$, $100 \mathrm{mM} \mathrm{NaNO}_{3}$ and $75 \mathrm{mM} \mathrm{HNO}_{3}$ dissolved in de-ionized water. For the deposition of $\mathrm{SnO}_{2}$ thin film, ITO/PEN without using a seed layer was placed in deposition bath and a constant voltage of $-0.4 \mathrm{~V} v s$. $\mathrm{Ag} / \mathrm{AgCl}$ reference electrode was applied for $120 \mathrm{~s}$ under $50{ }^{\circ} \mathrm{C}$.

\section{Fabrication of planar perovskite solar cells}

All fabrication processes except for the $\mathrm{SnO}_{2}$ electrodeposition were operated in an $\mathrm{N}_{2}$-filled glove box. A thin PCBM $\left(\sim 10 \mathrm{mg} \mathrm{ml}^{-1}\right.$ in chlorobenzene) layer was spin-coated onto the $\mathrm{SnO}_{2}$ coated- 
ITO/PEN substrate at $1000 \mathrm{rpm}$ for $60 \mathrm{~s}$. A $1 \mathrm{M}$ precursor solution of perovskite was prepared by dissolving lead iodide $\left(\mathrm{PbI}_{2}\right.$, $1 \mathrm{mmol})$ and methylammonium iodide $\left(\mathrm{CH}_{3} \mathrm{NH}_{3} \mathrm{I}, 1 \mathrm{mmol}\right)$ in a $7: 3 \mathrm{v} / \mathrm{v} \quad \gamma$-butyrolactone/dimethyl sulfoxide binary solvent mixture. The perovskite layer was prepared through the solvent washing technique by consecutive three steps: $500 \mathrm{rpm}$ for $5 \mathrm{~s}$, $1000 \mathrm{rpm}$ for $45 \mathrm{~s}$, and $5000 \mathrm{rpm}$ for $40 \mathrm{~s}$. During the spincoating, anhydrous toluene was in situ dropped at $20 \mathrm{~s}$ prior to the stop to facilitate the conversion of intermediate iodoplumbate anions to perovskite. ${ }^{45,46}$ The deposited perovskite film was subsequently annealed at $100{ }^{\circ} \mathrm{C}$ for $10 \mathrm{~min}$. The holetransporting layer (HTL) was deposited by spin coating a $40 \mathrm{mg}$ $\mathrm{ml}^{-1}$ concentration of $2,2^{\prime}, 7,7^{\prime}$-tetrakis $(N, N$-di- $p$-methoxyphenylamine)-9, $9^{\prime}$-spirobifluorene (spiro-OMeTAD) solution in chlorobenzene added with $33 \mu \mathrm{l}$ of lithium bis(trifluoromethanesulfonyl) imide (Li-TFSI) solution $(175.1 \mathrm{mg} \mathrm{Li}$ TSFI in $1 \mathrm{ml}$ acetonitrile, Sigma-Aldrich, 99.8\%) and $16 \mu \mathrm{l}$ of 4-tert-butyl pyridine ( $t \mathrm{BP}$ ) at the speed of $2000 \mathrm{rpm}$ for $60 \mathrm{~s}$. After depositing the HTL, the samples were stored inside a desiccator for a designated period of time. Finally, $\mathrm{Au}$ electrodes were thermally evaporated under high vacuum through a shadow mask to complete the device fabrication.

\section{Integration of fabricated device on textiles}

The integration of the fabricated flexible PVSCs on textiles was illustrated in scheme 1 . The $3 \mathrm{M}^{\mathrm{TM}}$ acrylic elastomer $\left(3 \mathrm{M}^{\mathrm{TM}}\right.$ $\mathrm{VHB}^{\mathrm{TM}}$ 4905) was used as received and the textiles were provided by Taiwan textile research institute (TTRI). The $3 \mathrm{M}^{\mathrm{TM}}$ elastomer was first attached on device's top side which deployed metal electrodes and then the whole device stack were reversed to adhere to the textile.

\section{Characterization}

Transmission electron microscope (TEM) images and selectedarea electron diffraction (SAED) pattern were taken using a microscope (FEI Tecnai G2 20) operated at $200 \mathrm{keV}$ to observe the crystallographic orientation of the electrodeposited $\mathrm{SnO}_{2}$ film. Scanning electron microscopy (SEM) imaging was taken using field emission scanning electron microscope (FE-SEM, JEOL JSM-6700F, Japan). Atomic force microscopy (AFM) imaging was performed on Innova (Bruker, Germany) AFM system in a tapping mode in air. The UV-vis transmission spectrum was recorded using a Hitachi U-4100 spectrophotometer. Photoluminescence (PL) spectra were measured by Horiba Fluorolog-3. For the current density-voltage $(J-V)$ measurement, the devices (with an active area of $0.04 \mathrm{~cm}^{2}$ ) were characterized under illumination of a Newport solar simulator (Newport Corp., Irvine, CA USA) with $\sim 800 \mathrm{~W} \mathrm{~m}^{-2}$ ( $\sim 0.8$ sun) intensity calibrated with a silicon reference diode. The $J-V$ characteristics were recorded using a source meter (Keithley 2400 , USA) in reverse (from the open-circuit voltage $\left(V_{\mathrm{OC}}\right)$ to the short-circuit current $\left(J_{\mathrm{SC}}\right)$ ) and forward (from $J_{\mathrm{SC}}$ to $V_{\mathrm{OC}}$ ) scan directions at a sweeping rate of $0.1 \mathrm{~V} \mathrm{~s}^{-1}$. Reference ITO/glassbased device was characterized using the same conditions.

Stability of the integrated device (with encapsulation) on textiles and reference device without encapsulation was monitored up to $425 \mathrm{~h}$. The studied devices were stored in an ambient environment at $25{ }^{\circ} \mathrm{C}$ with a relative humidity of $65 \%$. Water resistance test was carried out by immersing the integrated device into water without any further treatment. The tested device was took out at a certain period of time for performance checking and the residual water was gently wiped out by tissue prior to the $J-V$ measurement.

\section{Conflicts of interest}

There are no conflicts to declare.

\section{Acknowledgements}

The authors acknowledge the financial support from the Ministry of Science and Technology of Taiwan (MOST 105-2119M-002-008 \& 106-2218-E-002-021-MY2) and Top University Project from National Taiwan University (106R7322).

\section{Notes and references}

1 Q. Chen, H. Zhou, Z. Hong, S. Luo, H.-S. Duan, H.-H. Wang, Y. Liu, G. Li and Y. Yang, J. Am. Chem. Soc., 2014, 136, 622625.

2 G. Niu, X. Guo and L. Wang, J. Mater. Chem. A, 2015, 3, 8970.

3 M. B. Johnston and L. M. Herz, Acc. Chem. Res., 2016, 49, 146.

4 G. Xing, N. Mathews, S. Sun, S. S. Lim, Y. M. Lam, M. Grätzel, S. Mhaisalkar and T. C. Sum, Science, 2013, 342, 344.

5 W. S. Yang, J. H. Noh, N. J. Jeon, Y. C. Kim, S. Ryu, J. Seo and S. I. Seok, Science, 2015, 348, 1234.

6 N. J. Jeon, J. H. Noh, Y. C. Kim, W. S. Yang, S. Ryu and S. I. Seok, Solvent engineering for high-performance inorganic-organic hybrid perovskite solar cells, Nat. Mater., 2014, 13, 897.

7 S. T. Williams, A. Rajagopal, C.-C. Chueh and A. K. Y. Jen, J. Phys. Chem. Lett., 2016, 7, 811.

8 National Renewable Energy Laboratory (NREL), Research cell record efficiency chart, https://www.nrel.gov/pv/assets/ images/efficiency-chart.png, July 2017.

9 D. Bi, W. Tress, M. I. Dar, P. Gao, J. Luo, C. Renevier, K. Schenk, A. Abate, F. Giordano, J.-P. Correa Baena, J.-D. Decoppet, S. M. Zakeeruddin, M. K. Nazeeruddin, M. Grätzel and A. Hagfeldt, Sci. Adv., 2016, 2, e1501170.

10 H. Zhang, H. Azimi, Y. Hou, T. Ameri, T. Przybilla, E. Spiecker, M. Kraft, U. Scherf and C. J. Brabec, Chem. Mater., 2014, 26, 5190.

11 F. Giordano, A. Abate, J. P. C. Baena, M. Saliba, T. Matsui, S. H. Im, S. M. Zakeeruddin, M. K. Nazeeruddin, A. Hagfeldt and M. Graetzel, Nat. Commun., 2016, 7, 10379. 12 M.-C. Wu, S.-H. Chan, M.-H. Jao and W.-F. Su, Sol. Energy Mater. Sol. Cells, 2016, 157, 447.

13 H.-S. Kim and N.-G. Park, J. Phys. Chem. Lett., 2014, 5, 2927. 14 G. E. Eperon, V. M. Burlakov, P. Docampo, A. Goriely and H. J. Snaith, Adv. Funct. Mater., 2014, 24, 151.

15 J.-Y. Chen, C.-C. Chueh, Z. Zhu, W.-C. Chen and A. K.-Y. Jen, Sol. Energy Mater. Sol. Cells, 2017, 164, 47. 
16 B. J. Kim, D. H. Kim, Y.-Y. Lee, H.-W. Shin, G. S. Han, J. S. Hong, K. Mahmood, T. K. Ahn, Y.-C. Joo, K. S. Hong, N.-G. Park, S. Lee and H. S. Jung, Energy Environ. Sci., 2015, 8, 916.

17 D. Liu, M. K. Gangishetty and T. L. Kelly, J. Mater. Chem. A, 2014, 2, 19873.

18 H. Tan, A. Jain, O. Voznyy, X. Lan, F. P. García de Arquer, J. Z. Fan, R. Quintero-Bermudez, M. Yuan, B. Zhang, Y. Zhao, F. Fan, P. Li, L. N. Quan, Y. Zhao, Z.-H. Lu, Z. Yang, S. Hoogland and E. H. Sargent, Science, 2017, 355, 722.

19 S. S. Shin, E. J. Yeom, W. S. Yang, S. Hur, M. G. Kim, J. Im, J. Seo, J. H. Noh and S. I. Seok, Science, 2017, 14, 167.

20 E. H. Anaraki, A. Kermanpur, L. Steier, K. Domanski, T. Matsui, W. Tress, M. Saliba, A. Abate, M. Grätzel, A. Hagfeldt and J.-P. Correa-Baena, Energy Environ. Sci., 2016, 9, 3128.

21 W. Ke, G. Fang, Q. Liu, L. Xiong, P. Qin, H. Tao, J. Wang, H. Lei, B. Li, J. Wan, G. Yang and Y. Yan, J. Am. Chem. Soc., 2015, 137, 6730.

22 M. Kaltenbrunner, G. Adam, E. D. Głowacki, M. Drack, R. Schwödiauer, L. Leonat, D. H. Apaydin, H. Groiss, M. C. Scharber, M. S. White, N. S. Sariciftci and S. Bauer, Nat. Mater., 2015, 14, 1032.

23 J. A. Christians, P. A. M. Herrera and P. V. Kamat, J. Am. Chem. Soc., 2015, 137, 1530.

24 J. M. Frost, K. T. Butler, F. Brivio, C. H. Hendon, M. van Schilfgaarde and A. Walsh, Nano Lett., 2014, 14, 2584.

25 J. Yang, B. D. Siempelkamp, D. Liu and T. L. Kelly, ACS Nano, 2015, 9, 1955.

26 H. Kim, K.-G. Lim and T.-W. Lee, Energy Environ. Sci., 2016, 9, 12.

27 T. A. Berhe, W.-N. Su, C.-H. Chen, C.-J. Pan, J.-H. Cheng, H.-M. Chen, M.-C. Tsai, L.-Y. Chen, A. A. Dubale and B.-J. Hwang, Energy Environ. Sci., 2016, 9, 323.

28 Y. Han, S. Meyer, Y. Dkhissi, K. Weber, J. M. Pringle, U. Bach, L. Spiccia and Y.-B. Cheng, J. Mater. Chem. A, 2015, 3, 8139. 29 D. Yu, Y.-Q. Yang, Z. Chen, Y. Tao and Y.-F. Liu, Opt. Commun., 2016, 362, 43.
30 J.-S. Park, H. Chae, H. K. Chung and S. I. Lee, Semicond. Sci. Technol., 2011, 26, 034001.

31 M. Jørgensen, K. Norrman and F. C. Krebs, Sol. Energy Mater. Sol. Cells, 2008, 92, 686.

32 J. A. Hauch, P. Schilinsky, S. A. Choulis, S. Rajoelson and C. J. Brabec, Appl. Phys. Lett., 2008, 93, 103306.

33 W. J. Potscavage, S. Yoo, B. Domercq and B. Kippelen, Appl. Phys. Lett., 2007, 90, 253511.

34 C.-Y. Chang, C.-T. Chou, Y.-J. Lee, M.-J. Chen and F.-Y. Tsai, Org. Electron., 2009, 10, 1300.

35 K. Shin, J. Park and C. Lee, Thin Solid Films, 2016, 598, 95.

36 P.-W. Liang, C.-C. Chueh, S. T. Williams and A. K.-Y. Jen, Adv. Energy Mater., 2015, 5, 1402321.

37 J. You, Z. Hong, Y. M. Yang, Q. Chen, M. Cai, T.-B. Song, C.-C. Chen, S. Lu, Y. Liu, H. Zhou and Y. Yang, ACS Nano, 2014, 8, 1674.

38 F. Fu, T. Feurer, T. Jäger, E. Avancini, B. Bissig, S. Yoon, S. Buecheler and A. N. Tiwari, Nat. Commun., 2015, 6, 8932. 39 H.-W. Chen, T.-Y. Huang, T.-H. Chang, Y. Sanehira, C.-W. Kung, C.-W. Chu, M. Ikegami, T. Miyasaka and K.-C. Ho, Sci. Rep., 2016, 6, 34319.

40 O. Malinkiewicz, A. Yella, Y. H. Lee, G. M. Espallargas, M. Graetzel, M. K. Nazeeruddin and H. J. Bolink, Nat. Photonics, 2014, 8, 128.

41 H.-S. Kim, I.-H. Jang, N. Ahn, M. Choi, A. Guerrero, J. Bisquert and N.-G. Park, J. Phys. Chem. Lett., 2015, 6, 4633.

42 B. A. Nejand, V. Ahmadi, S. Gharibzadeh and H. R. Shahverdi, ChemSusChem, 2016, 9, 302.

43 D. Bryant, N. Aristidou, S. Pont, I. Sanchez-Molina, T. Chotchunangatchaval, S. Wheeler, J. R. Durrant and S. A. Haque, Energy Environ. Sci., 2016, 9, 1655.

44 Y. Zhao, J. Wei, H. Li, Y. Yan, W. Zhou, D. Yu and Q. Zhao, Nat. Commun., 2016, 7, 10228.

45 D. Bae, A. Palmstrom, K. Roelofs, B. Mei, I. Chorkendorff, S. F. Bent and P. C. K. Vesborg, ACS Appl. Mater. Interfaces, 2016, 8, 14301.

46 N. Ahn, D.-Y. Son, I.-H. Jang, S. M. Kang, M. Choi and N.-G. Park, J. Am. Chem. Soc., 2015, 137, 8696. 